\title{
Effect of Temperature on the Incubation Period and Leaf Colonization in Bacterial Blight of Anthurium
}

\author{
R. Fukui, H. Fukui, and A. M. Alvarez
}

Department of Plant Pathology, University of Hawaii at Manoa, Honolulu 96822-2279.

Accepted for publication 30 July 1999.

\begin{abstract}
Fukui, R., Fukui, H., and Alvarez, A. M. 1999. Effect of temperature on the incubation period and leaf colonization in bacterial blight of anthurium. Phytopathology 89:1007-1014.

Effect of temperature on leaf colonization in anthurium blight was studied using a bioluminescent strain of Xanthomonas campestris pv. dieffenbachiae. In a susceptible cultivar, colonization of leaf tissues (monitored by detection of bioluminescence) and symptom development (assessed visually) advanced rapidly at higher temperatures. For a susceptible cultivar, there was a linear relationship between degree-days and percent leaf area colonized by the pathogen, indicating that leaf colonization in a susceptible cultivar was a direct function of the cumulative effect of temperature. The degree-day intercept of the regression line represented the

indicated the increase of leaf colonization per degree-day. There also was a linear relationship between the logarithm of degree-days and the logarithm of percent leaf area showing visible symptoms in a susceptible cultivar. The degree-day intercept of this relationship represented the incubation period (about 500 degree-days). The degree-days required to detect bioluminescence was not considerably different between susceptible and resistant cultivars. However, the subsequent rates of leaf colonization were significantly lower for a resistant cultivar than for a susceptible cultivar in all temperature regimes. The results suggest that multiplication of the pathogen in the leaf tissues is optimized in the susceptible cultivar. In contrast, in the resistant cultivar, the defense mechanisms overshadow the temperature effect. The differential response to temperatures may be an additional indicator of cultivar susceptibility.
\end{abstract} time from inoculation to detection of bioluminescence, and the slope
Bacterial blight of anthurium (Anthurium andraeanum Linden), caused by Xanthomonas campestris pv. dieffenbachiae $(=X$. axonopodis pv. dieffenbachiae) (21), is an important disease worldwide. The disease caused serious losses to the Hawaiian anthurium industry in the 1980s $(17,18)$. The combined effects of temperature and free water appeared to trigger the epidemic of blight of anthurium. It was observed in recent field experiments conducted at Hilo on the island of Hawaii, the major anthurium production site, that disease spread coincided with a prolonged rainy period (R. Fukui, H. Fukui, and A. M. Alvarez, unpublished data). However, several growers reported that entire plantings were devastated by the disease even though the plants were grown inside glasshouses. Other growers recently observed that disease incidence was higher in a section of a field where the plants were sheltered from rain with a polycarbonate roofing structure than in adjacent areas covered only with shade cloth (saran), although the same cultivar was planted in the entire field.

The higher incidence of disease observed under such roofing structures was attributed to higher temperatures $(10,11)$. In general, multiplication of the bacterial pathogen in host leaf tissues and symptom development in infected leaves are greater at higher temperatures $(4,5,12,13,20,24)$. Test results for anthuriums using growth chambers also demonstrated that disease incidence (percentage of plants showing symptoms) increased faster in plants grown at 28 or $30^{\circ} \mathrm{C}$ than those at 20 or $22^{\circ} \mathrm{C}$, but eventually reached $100 \%$ at all temperatures $(2,9)$. However, it was not known whether high temperature shortened the incubation period, resulting in enhanced symptom expression, or more infections occurred at higher temperatures under field conditions.

The disease is less serious now than in the 1980s, but is still difficult to eradicate because the pathogen is harbored in symptomless

Corresponding author: R. Fukui; E-mail address: ryo@ hawaii.edu

Publication no. P-1999-0920-02R

(C) 1999 The American Phytopathological Society plants $(6,7,14)$. Latently infected plants can be shipped or acquired, providing inoculum sources for a new disease epidemic. A recent report that plant materials shipped from the Netherlands to India were infected by $X$. campestris pv. dieffenbachiae (16) emphasizes the risks involved in shipping. Measurement of incubation period and information on the factors associated with symptom development are needed to improve the current strategy for crop protection.

Symptom expression should be assessed in relation to sites of leaf colonization by the pathogen, because natural water congestion in leaf tissues frequently occurs in anthurium and resembles the initial phase of symptom development. A bioluminescent strain of $X$. campestris pv. dieffenbachiae allows the nondestructive detection of sites of leaf colonization (7). The length of the incubation period and effect of temperature on leaf colonization can be studied precisely by combining bioluminescence detection with measurements of visual symptoms. Two methods are essential for monitoring leaf colonization because, in leaves of susceptible cultivars, sites of leaf colonization advance well beyond areas showing symptoms (7).

The objectives of this study were to examine the effects of temperature on incubation period (the time between inoculation and symptom development) and on subsequent progress of bacterial blight in susceptible and resistant cultivars by simultaneously monitoring symptom expression and colonization of leaf tissues by the pathogen. Tests were conducted under glasshouse conditions as well as in temperature-controlled environmental growth chambers. Preliminary results of this study were reported (8).

\section{MATERIALS AND METHODS}

The pathogen and inoculum preparation. A bioluminescent strain, V108LRUH1, of $X$. campestris pv. dieffenbachiae (6) was used for all tests. Inoculum for plant inoculation tests was prepared by growing V108LRUH1 on peptone glucose medium (1.0\% peptone, $0.5 \%$ glucose, and $1.7 \%$ agar) for 2 days at $28^{\circ} \mathrm{C}$. Cells were suspended in sterile distilled water, and the cell density was ad- 
justed to an optical density at $600 \mathrm{~nm}$ of 0.1 (about $10^{8} \mathrm{CFU} / \mathrm{ml}$ ) using a spectrophotometer. This suspension was diluted 100 -fold with sterile distilled water and used as an inoculum.

Plant materials and growth conditions for acclimatization. Plants of cvs. Kalapana (UH1016) and Marian Seefurth (H33) potted in cinder medium were obtained from growers on the island of Hawaii. The cvs. Kalapana and Marian Seefurth are representative of resistant and susceptible cultivars, respectively, as judged by evaluation for their susceptibility to leaf infection by V108LRUH1 (7). Plants were grown in a glasshouse shaded with two layers of saran cloth and watered every other day until use. To assure that the plants were free of local strains of the pathogen, all newly acquired plants were acclimatized in an isolated section of the glasshouse for at least 4 months before being used for experiments. Plants that developed disease symptoms were discarded during acclimatization. For resistant cultivars, leaves with symptoms were removed and the contaminated plants were further acclimatized for an additional 4 months.

Plant inoculation tests in three glasshouse sections with different temperature ranges. Three weeks before inoculation, all plants were taken out of their original pots and all cinder particles were removed from the roots. The bare-rooted plants were planted in pots $(10 \times 10 \mathrm{~cm})$ with new cinder medium. All fertilizer pellets loosely adhering to the roots were removed during the process of transplanting. This was necessary because pelleted fertilizers release formulated nutrients faster at higher temperatures, and higher amounts of nitrogen may affect disease development (8). All plants were watered with distilled water, and seven plants per cultivar were placed in three separate sections of the glasshouse (I, II, and III), each shaded with two layers of saran cloth. The three sections were identical in shape and dimensions but were different in temperature range. Glasshouse section I was equipped with a waterdrip cooling system and was the coolest of the three sections. Part of glasshouse section II was cooled with an electric air conditioner, and this section was intermediate in temperature range between sections I and III. The glasshouse section III was not equipped with a cooling system and had the highest temperature range. The maximum light intensity (wave length of 400 to $700 \mathrm{~nm}$ ) at the plant canopy measured at 2:00 p.m. on sunny days, using a Solar Monitor (model LI-1776; LI-COR, Inc., Lincoln, NE), was 20 to $30 \mu \mathrm{mol} \mathrm{m}{ }^{-2} \mathrm{~s}^{-1}$ in all sections.

For 3 weeks prior to inoculation, all plants were fertilized once a week with modified Hoagland's solution (7); nitrogen was eliminated by substituting $\mathrm{Ca}\left(\mathrm{NO}_{3}\right)_{2}$ and $\mathrm{KNO}_{3}$ with $\mathrm{CaCl}_{2}$ and $\mathrm{KCl}$ at equivalent molar concentrations. Between fertilizations, plants were
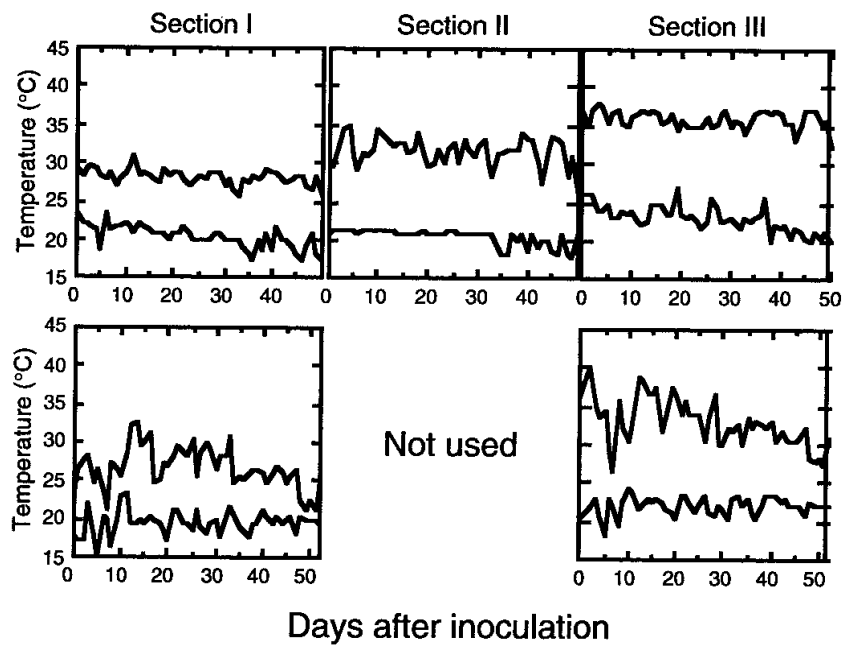

Fig. 1. Daily minimum and maximum temperatures in glasshouse sections I, II, and III during the course of the first (top) and second (bottom) experiment. Section II of the glasshouse was not used in the second experiment. watered three times with distilled water. Two days before inoculation, all plants were fertilized with modified Hoagland's solution containing $70 \mu \mathrm{g}$ of nitrogen (in the form of $\mathrm{NH}_{4} \mathrm{NO}_{3}$ ) per $\mathrm{ml}$ at the rate of $150 \mathrm{ml}$ per pot. Any remaining fertilizer solution was collected in a plastic saucer placed underneath the pot and reapplied to the plant the next day. All plants were then individually placed in plastic bags and spray-inoculated with a cell suspension of V108LRUH1 (containing about $10^{6} \mathrm{CFU} / \mathrm{ml}$ ). Inoculated plants were kept wet in plastic bags overnight to assure that the pathogen invaded the leaves. The next day, the plants were removed from the bags and returned to the same glasshouse sections. Fertilization with modified Hoagland's solution containing $70 \mu \mathrm{g}$ of nitrogen per ml was repeated 5 days after inoculation and weekly thereafter, as described above, until the end of the experiment. Plants were watered three times between fertilizations. The daily minimum and maximum temperatures in the three glasshouse sections were recorded during the experiment (Fig. 1).

The experiment was repeated using only glasshouse sections I and III. All procedures were the same as described above, except that the experiment was conducted with eight plants (replicates) per temperature range for each cultivar. The daily minimum and maximum temperatures in the two glasshouse sections were recorded during the experiment (Fig. 1). In two sets of experiments, ambient relative humidity in the three glasshouse sections was measured using TH Trace temperature-humidity recorders (The Dickson Company, Addison, IL), and it fluctuated from about 30 to $100 \%$ as a function of temperature. This was similar to the humidity levels (about 40 to $100 \%$ ) typically occurring in Hilo, HI, the major anthurium production site (9).

Plant inoculation tests in environmental growth chambers with different temperature ranges. Four environmental growth chamber units (Puffer Hubbard Environmental; Rheem Manufacturing Company, Asheville, NC) were used in the experiment. Chambers 1 and 4 were larger in size $(250 \times 130 \times 210 \mathrm{~cm}$ for the length, width, and height of the chamber compartment; model CEC511$38-1)$ than were chambers 2 and $3(120 \times 75$ by $160 \mathrm{~cm}$; model CEC36-10-1). Temperatures (minimum and maximum) in growth chambers $1,2,3$, and 4 were adjusted to 19 to 27,23 to 31,19 to 35 , and 27 to $35^{\circ} \mathrm{C}$, respectively, with the identical hourly programming (Fig. 2). Lights were provided by incandescent and fluorescent lights at the ratio of 1:3, and the light intensity at the plant

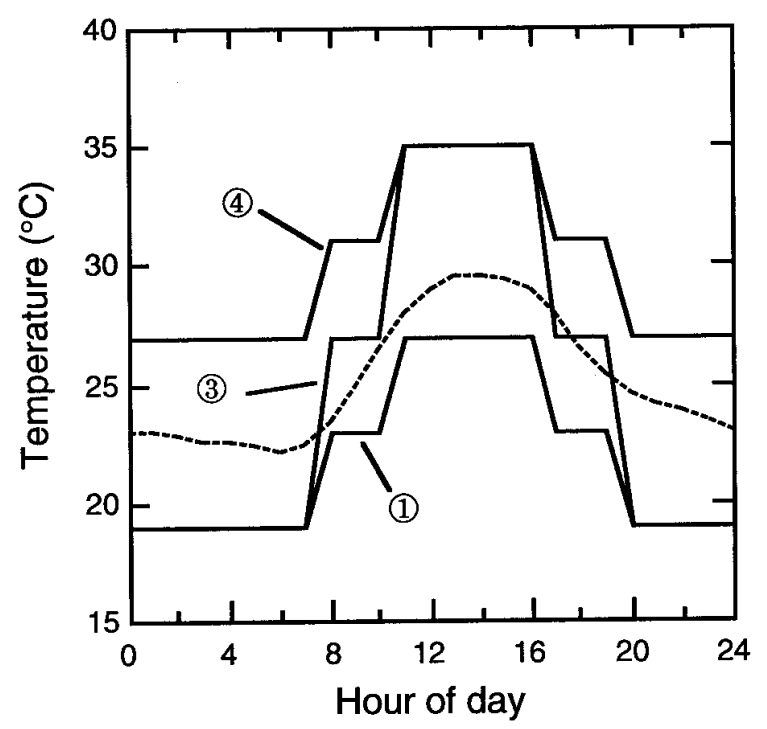

Fig. 2. Temperature regimes programmed for four environmental growth chambers. Temperature settings (minimum-transition-maximum in ${ }^{\circ} \mathrm{C}$ ) in chambers $1,2,3$, and 4 were programmed as $19-23-27^{\circ} \mathrm{C}$ (1), $23-27-31^{\circ} \mathrm{C}$ (not shown), $19-27-35^{\circ} \mathrm{C}$ (3), and $27-31-35^{\circ} \mathrm{C}$ (4), respectively. The broken line indicates the average hourly temperature in glasshouse section I (determined over a 3-week period in April to May). 
canopy was lowered to the same levels as in the glasshouse sections with one or two layers of shade cloth hanging above the plants. The maximum light intensity measured at the center (and at the four corners) of the chamber compartment was 24 (27 to 31), 33 ( 27 to 28 ), 31 (24 to 27 ), and 24 (27 to 31$) \mu \mathrm{mol} \mathrm{m} \mathrm{m}^{-2} \mathrm{~s}^{-1}$ in chambers $1,2,3$, and 4 , respectively.

Plants of cvs. Kalapana and Marian Seefurth were acclimatized for 3 weeks in the four chambers, inoculated with V108LRUH1, and incubated in the chambers as described above. The experiment was conducted with eight plants (replicates) per temperature range for each cultivar. During the experiment, temperatures in the four chambers were monitored with minimum-maximum thermometers, a TH Trace temperature-humidity recorder, or both to assure that error was within $\pm 1{ }^{\circ} \mathrm{C}$ from the programmed temperature. To avoid an excessive drop in relative humidity in the chambers operating at high temperatures, trays of water were placed inside the chambers, and water levels were maintained daily by adding water as needed. The relative humidity in the four chambers ranged from 30 to $90 \%$ as a function of temperature.

Measurement of leaf area colonized by the pathogen and symptom development. Leaf area colonized by the pathogen was measured by detecting bioluminescence emitted from V108LRUH1. Bioluminescence from infected leaves was detected by attaching X-ray films (Fuji "New RX" medical X-ray film; Fuji Photo Film Co., Kanagawa, Japan) firmly to the bottom sides of the leaves and exposing the films in the dark for $7 \pm 1 \mathrm{~h}$. The percent value for the areas exposed by bioluminescence (black areas on developed films) representing leaf tissues colonized by the pathogen was estimated using area diagrams representing various percentages of infected leaf areas (7) and was expressed as percent leaf area colonized (\%LAC). The detection threshold of this technique was $>10^{6} \mathrm{CFU} / \mathrm{cm}^{2}$ (or $>10^{4} \mathrm{CFU} / \mathrm{mm}^{2}$ ) of leaf tissue, because infected leaf tissues emitting bioluminescence contained at least $10^{6} \mathrm{CFU}$ of the pathogen per $\mathrm{cm}^{2}$ of leaf tissue, regardless of the presence or absence of symptom expression (7).

Leaf area showing visible symptoms was measured by tracing the margins of visible symptoms onto transparent polycarbonate sheets. The areas with symptoms (and the total leaf area) were measured with a computer digitizer program (Sigma Scan; Jandel Scientific Software, Corte Madera, CA) to calculate percent leaf area with symptoms (\%LAS). A visible symptom was defined as watersoaked spots and lesions. Subsequent necrotic areas were also considered "visible symptoms," because water-soaked spots and lesions became necrotic in transition as infection advanced. Chlorosis was often seen beyond necrotic areas, but was not considered a visible symptom because the margins of chlorotic areas were not well defined. Visible symptoms traced onto transparent sheets were compared with images of bioluminescence on X-ray film.

Normally, \%LAC and \%LAS were measured on the two youngest leaves per plant, because the extent of leaf colonization was greatest in the two youngest leaves among leaves of all ages (7). For some plants, measurement was made on only one leaf (second-
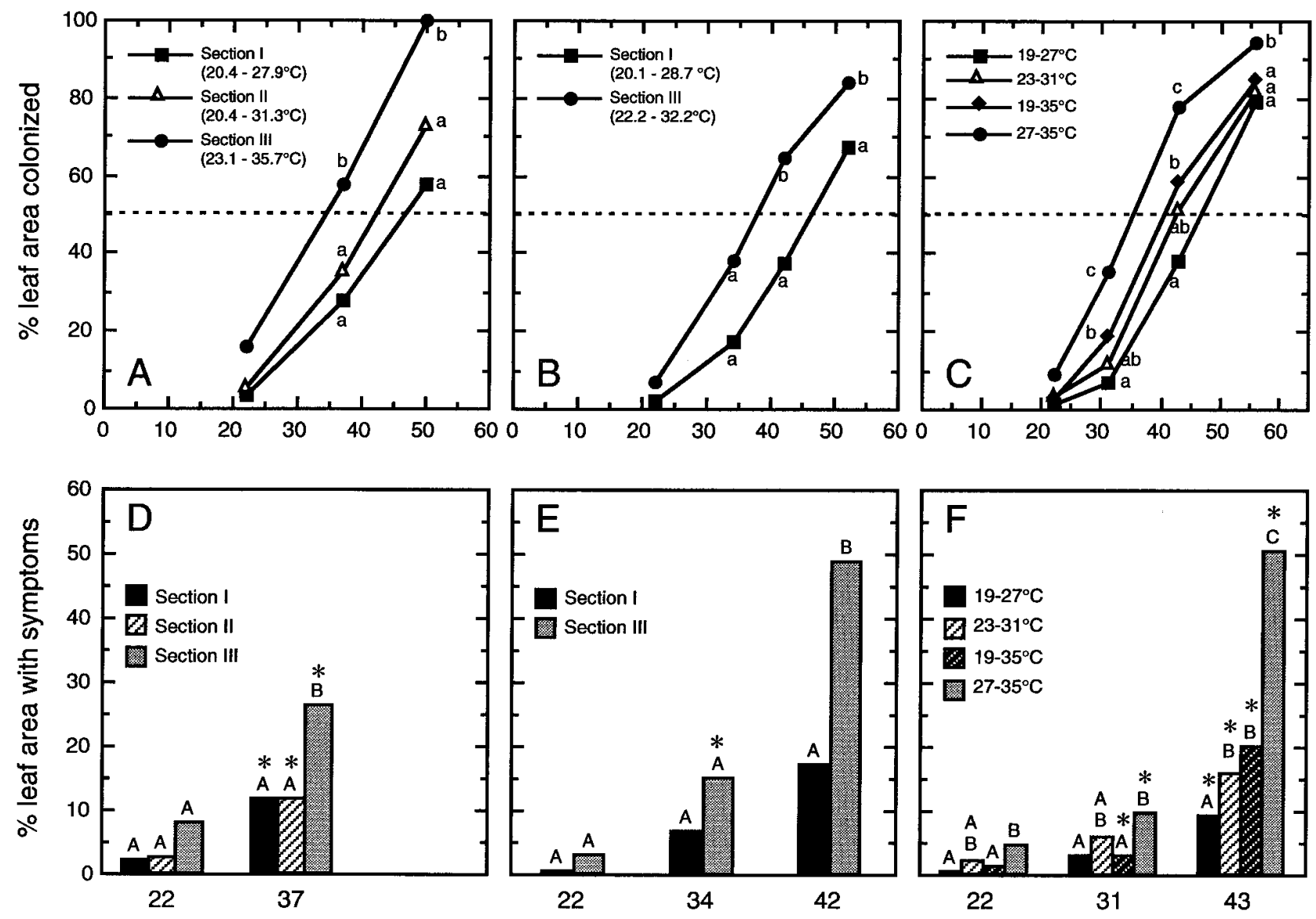

\section{Days after inoculation}

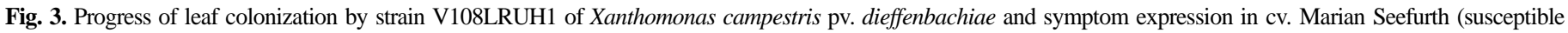

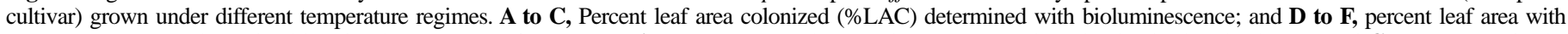

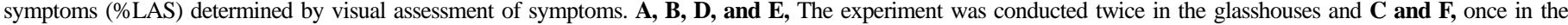

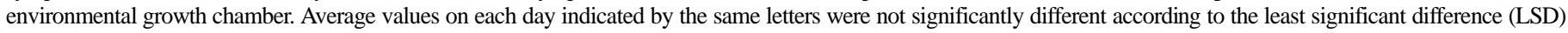

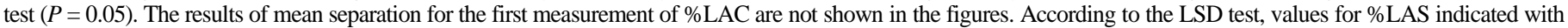
asterisks in $\mathbf{D}, \mathbf{E}$, and $\mathbf{F}$ were significantly lower $(P=0.05)$ than the corresponding values for \%LAC in $\mathbf{A}, \mathbf{B}$, and $\mathbf{C}$. Values were means of seven or eight replicates. 
youngest leaf) per plant because the youngest leaf was in the stage of differentiation, unfolding, or expanding at the time of inoculation. When measurements were made on two leaves, the larger value was used for data analysis. The \%LAC was recorded at $5 \%$ increments, and \%LAS was recorded at $1 \%$ increments.

Inoculated plants were observed every day for the presence of visible symptoms on the leaves. In all three experiments, the first measurements of \%LAC and \%LAS were made 22 days after inoculation, because apparent disease symptoms began to develop at this time on most of the inoculated plants grown under the coolest condition in each experiment. The \%LAC was measured three times in the first glasshouse experiment (22, 37, and 50 days after inoculation), four times in the second glasshouse experiment $(22,34,42$, and 52 days after inoculation) and in the growth chamber test $(22,31,43$, and 56 days after inoculation). The \%LAS was not measured on the last measurement in each experiment, because the extent of disease symptoms was usually too severe for accurate measurement of \%LAS.

Statistical analysis. Data for \%LAC and \%LAS were first analyzed separately for each cultivar. Prior to statistical analysis, percentage data were transformed by arcsine-transformation. The transformed data were submitted to analysis of variance (ANOVA) to examine the effect of temperature, the main factor. Assessment day was considered as the repeated measure in a factorial arrangement. Means were separated by the protected least significant dif- ference (LSD) test. Data were then reanalyzed by the three-way (temperature, assessment method, and day) ANOVA. Means for the two assessment methods were compared by the LSD test.

To examine the relationship between temperature and leaf colonization or symptom development, degree-day in Celsius was calculated for each experiment by degree-day $=\sum\left(T_{\min }+\mathbf{T}_{\max }\right) / 2$, in which $T_{\min }$ and $T_{\max }$ are the daily minimum and maximum temperatures. Linear regression was used to analyze the relationship between degree-days and \%LAC or \%LAS (using individual, nontransformed data) for each experiment. The significance of a linear relationship was examined by $t$ test and $F$ test for lack of fit in linear regression (15). Slope values of regressed lines were compared by calculating a $95 \%$ confidence interval for each slope value. Data for percent leaf area with symptoms from three experiments were then combined and reanalyzed by regression analysis (using the mean values of seven or eight replicates) to examine the overall trend in the relationship between degree-days and symptom development. To produce a straight line, both $x$ and $y$ values were logarithmically transformed. Percentage values that were less than $1 \%$ were rated zero.

\section{RESULTS}

Effects of temperature on leaf colonization by V108LRUH1 and symptom expression. For cv. Marian Seefurth, the extent of leaf col-
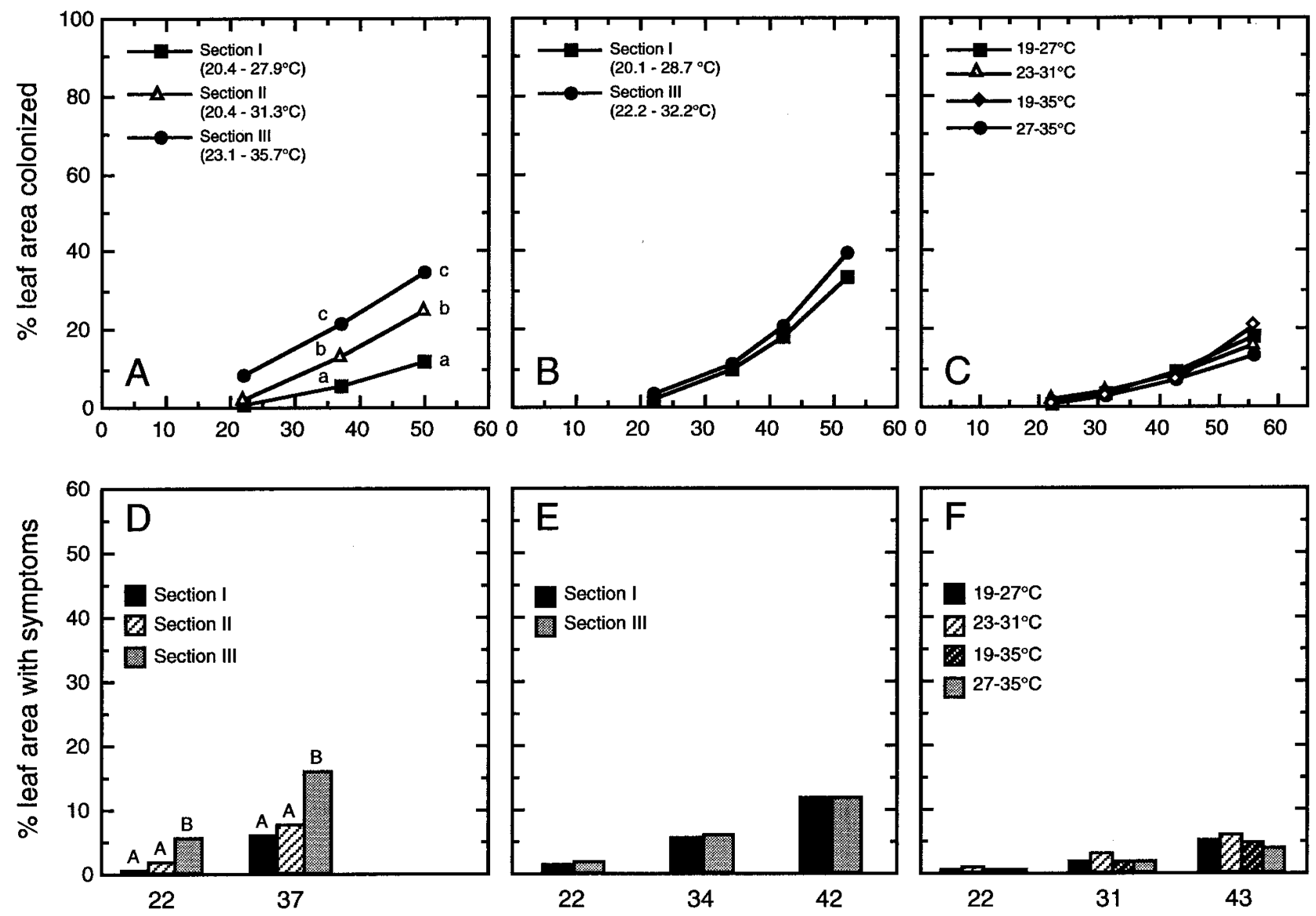

Days after inoculation

Fig. 4. Progress of leaf colonization by strain V108LRUH1 of Xanthomonas campestris pv. dieffenbachiae and symptom expression in cv. Kalapana (resistant cultivar) grown under different temperature regimes. A to C, Percent leaf area colonized (\%LAC) determined with bioluminescence; and $\mathbf{D}$ to $\mathbf{F}$, percent leaf area with symptoms (\%LAS) determined by visual assessment of symptoms. A, B, D, and E, The experiment was conducted twice in the glasshouses and $\mathbf{C}$ and F, once in the environmental growth chamber. Average values on each day indicated by the same letters were not significantly different according to the least significant difference (LSD) test $(P=0.05)$. The results of mean separation for the first measurement of \%LAC are not shown in $\mathbf{A}$. The effect of temperature was not significant for both \%LAC and \%LAS in $\mathbf{B}$ and $\mathbf{E}$, the second glasshouse test and $\mathbf{C}$ and $\mathbf{F}$, the growth chamber test. None of the values for \%LAS were significantly different from the corresponding values for \%LAC. Values were means of seven or eight replicates. 
onization determined with bioluminescence advanced faster at higher temperatures in all three experiments (Fig. 3A to C). The \% LAC for the plants grown at the highest temperatures were significantly greater than the \%LAC for those grown at the lower temperatures. Significant differences were evident as early as 31 days after inoculation (Fig. 3C) and as late as 42 days after inoculation (Fig. 3B). For cv. Marian Seefurth, visual symptoms were expressed earlier in plants grown at high temperatures than in plants grown at low temperatures. By the last visual assessment (37 to 42 days after inoculation), \%LAS was significantly greater at high temperatures than at low temperatures in all three experiments (Fig. 3D to F). In many cases, \%LAS was significantly lower than the corresponding \%LAC.

For cv. Kalapana, leaf colonization advanced faster at high temperatures than at low temperatures in the first glasshouse test (Fig.

TABLE 1. Average minimum and maximum temperatures in two glasshouse sections and four environmental growth chambers and their relationship to leaf colonization in Anthurium andraeanum cv. Marian Seefurth

\begin{tabular}{|c|c|c|c|c|c|}
\hline \multirow[b]{2}{*}{ Test condition } & \multirow[b]{2}{*}{ Temperature range } & \multicolumn{2}{|c|}{ Average temperature $\left({ }^{\circ} \mathrm{C}\right)^{\mathrm{a}}$} & \multirow[b]{2}{*}{$\mathrm{LAC}_{50}{ }^{\mathrm{b}}$} & \multirow[b]{2}{*}[(\mathrm{A}+\mathrm{B})/2]{$\times \mathrm{LAC}_{50}(\mathrm{C})$} \\
\hline & & Minimum (A) & Maximum (B) & & \\
\hline \multirow[t]{2}{*}{ Glasshouse, first experiment } & Low & $20.4 \pm 1.3$ & $27.9 \pm 1.4$ & 47 & $1,135.1$ \\
\hline & Intermediate & $20.4 \pm 1.0$ & $31.3 \pm 2.4$ & 42 & $1,085.7$ \\
\hline \multirow[t]{2}{*}{ Glasshouse, second experiment } & Low & $20.1 \pm 1.6$ & $28.7 \pm 2.8$ & 46 & $1,122.4$ \\
\hline & High & $22.1 \pm 1.3$ & $32.2 \pm 4.3$ & 38 & $1,031.7$ \\
\hline \multirow[t]{2}{*}{ Growth chamber } & $19-27^{\circ} \mathrm{C}$ & 19 & 27 & 47 & 1,081 \\
\hline & $27-35^{\circ} \mathrm{C}$ & 27 & 35 & 36 & 1,116 \\
\hline Average & & & & & $1,093.5 \pm 40.5^{\mathrm{d}}$ \\
\hline
\end{tabular}

a Indicated with one standard deviation when appropriate.

${ }^{\mathrm{b}}$ Number of days at which $50 \%$ of the leaf area is colonized by the pathogen, estimated from the infection curves in Figure 3.

${ }^{c}$ The $\mathrm{C}$ values are not significantly different, as judged by the $95 \%$ confidence interval based on two standard deviations (80.9).

$\mathrm{d}$ The average value is expressed with one standard deviation.
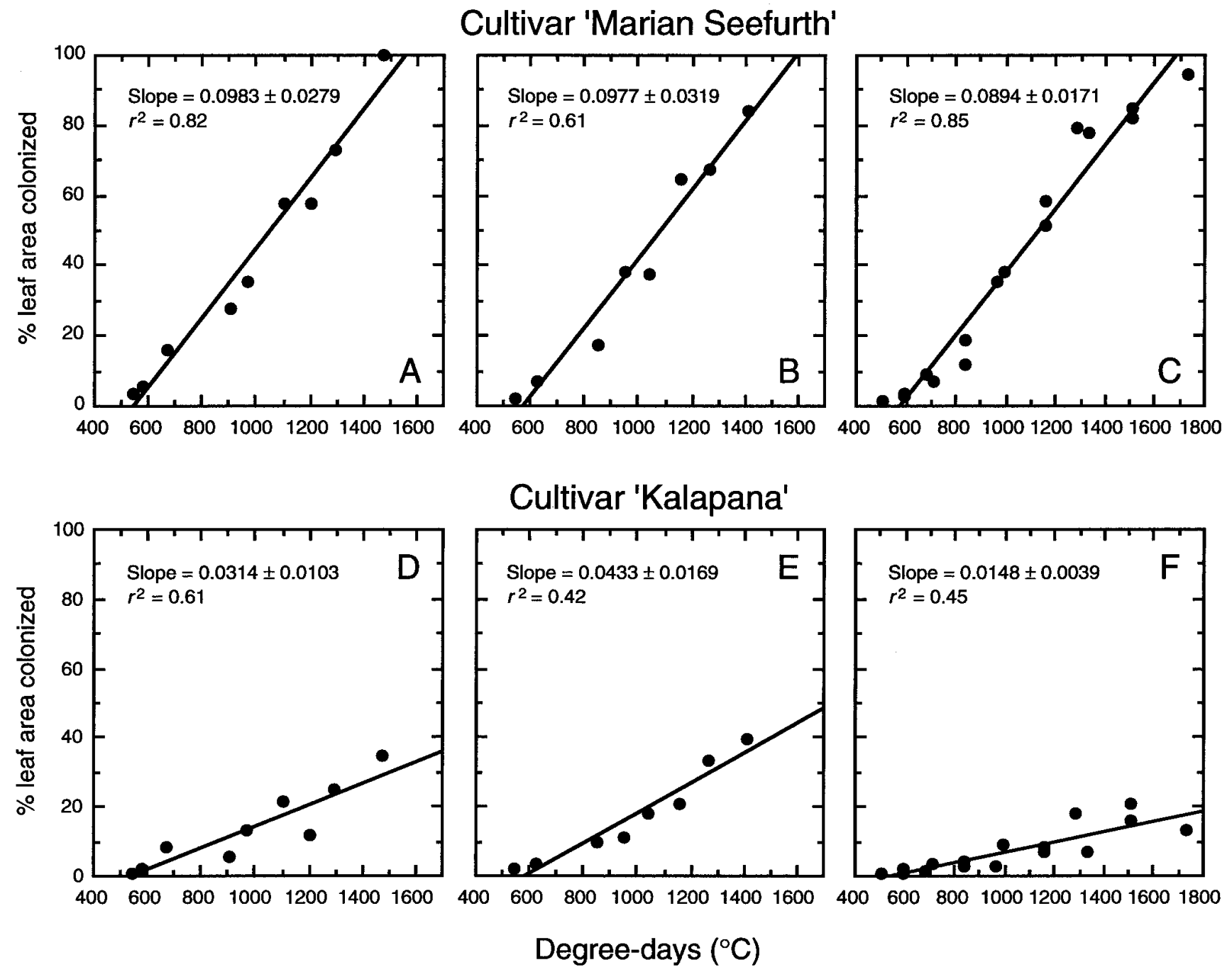

Fig. 5. Relationships between degree-days in ${ }^{\circ} \mathrm{C}$ and percent leaf area colonized for $\mathbf{A}$ to $\mathbf{C}$, cv. Marian Seefurth and $\mathbf{D}$ to $\mathbf{F}$, cv. Kalapana. Slope values shown are accompanied with the respective values of $95 \%$ confidence interval. Each data point represents the mean of seven or eight replicates. A and D, First glasshouse experiment. B and E, Second glasshouse experiment. $\mathbf{C}$ and $\mathbf{F}$, Growth chamber experiment. All linear trends were significant at $P=0.01$. 
4A), but it was not affected by temperature in two other experiments (Fig. 4B and C). Difference in \%LAS was significant only in the first glasshouse experiment (Fig. 4D). None of the values for \%LAS were significantly different from the corresponding $\%$ LAC (Fig. 4D to F).

In both cvs. Marian Seefurth and Kalapana plants, bioluminescence and visible symptoms were always detected simultaneously at the initial stage of disease development. Later, the infected areas, determined by bioluminescence, advanced well beyond the area of visible symptoms expressed by cv. Marian Seefurth. In cv. Kalapana, however, the infected areas determined by bioluminescence were mostly restricted to areas showing visible symptoms.

Relationship between temperature and leaf colonization by V108LRUH1 monitored with bioluminescence. For cv. Marian Seefurth, there was a reciprocal relationship between temperature and days required to reach a certain $\%$ LAC. The average $T_{\min }$ and $T_{\max }$ in the three experiments and the number of days required to reach a \% LAC of $50\left(\mathrm{LAC}_{50}\right)$ under each growth condition (estimated from the infection curves in Fig. 3) are shown in Table 1.
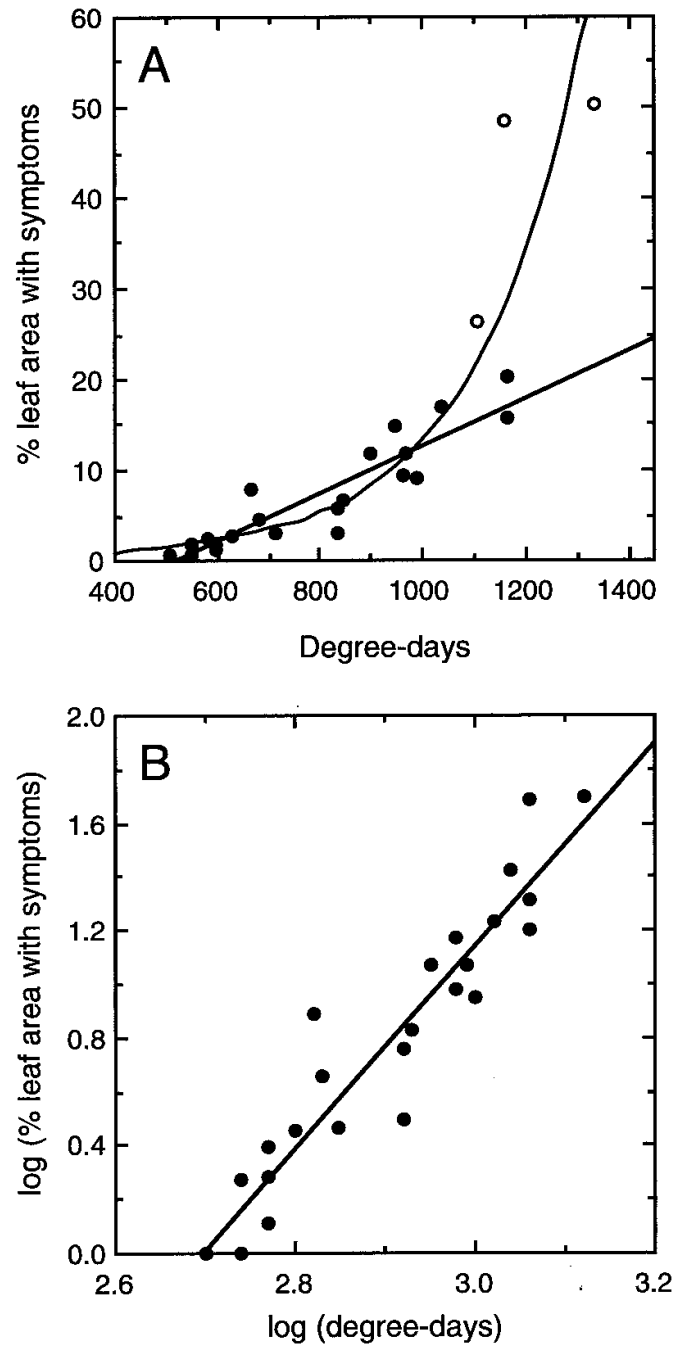

Fig. 6. Relationships between degree-days in ${ }^{\circ} \mathrm{C}$ and percent leaf area with symptoms for cv. Marian Seefurth. Regression lines were calculated by combining the results of three experiments. Each data point represents a mean of seven or eight replicates. A, Two-phase relationships obtained for nontransformed data. An exponential relationship $\left(y=0.109 \times 10^{2.075 x}, r^{2}=0.86\right)$ was calculated from all data points. A linear relationship $(y=0.0264 x-13.721$, $r^{2}=0.83$ ) was calculated by excluding one data point at the highest degreeday for each of the three experiments (indicated by $\bigcirc$ ). B, A linearized relationship by log-transformation. The linear relationship $(y=3.775 x-10.175$, $r^{2}=0.89$ ) was calculated from all data points.
The averages of minimum and maximum temperatures multiplied by the values of $\mathrm{LAC}_{50}$ were within the range of 1,029 to 1,135 in all cases. When values of \% LAC were plotted versus degree-days, there was a linear relationship in all three experiments (Fig. 5A to C). According to $t$ tests, all three linear trends were significant at $P=0.01$. As judged by the $95 \%$ confidence intervals, the three slopes for cv. Marian Seefurth were not significantly different from each other, indicating a consistent relationship in this cultivar. The degree-day intercepts for the three regression lines (Fig. 5A to $\mathrm{C}$ ) were 544,573 , and 568 degree-days, respectively.

The cv. Kalapana was not as responsive to temperature changes as cv. Marian Seefurth, and infection rates in cv. Kalapana did not appear to be affected by temperature in two of three experiments (Fig. 4B and C). However, there was a significant linear relationship $(P=0.01)$ between degree-days and \%LAC in all three tests (Fig. 5D to F). The slope for cv. Kalapana in the growth chamber experiment (Fig. 5F) was significantly lower than the slopes in two other experiments (Fig. 5D and E). All slopes for cv. Kalapana were significantly different from any slopes for cv. Marian Seefurth. The degree-day intercepts for the three regression lines (Fig. $5 \mathrm{D}$ to $\mathrm{F}$ ) were 535,584 , and 534 degree-days, respectively.

Relationship between temperature and symptom development. For cv. Marian Seefurth, the overall trend between degreedays and symptom development obtained by compiling the results of the three experiments revealed that \%LAS increased exponentially as degree-days increased (Fig. 6A). This exponential relationship was linearized when both variables were logarithmically transformed (Fig. 6B). However, there was also a linear relationship between nontransformed values of degree-days and \%LAS, when the data point for the highest degree-day in each experiment (three data points above 25\%) was omitted from regression analysis (Fig. 6A). The degree-day intercepts of the transformed and nontransformed regression lines were 2.7 log degree-days and 520 degree-days, respectively.

Data for cv. Kalapana were not analyzed, because neither the infection rate nor symptom development were affected by temperature in two of the three experiments.

\section{DISCUSSION}

Progress of leaf colonization by the pathogen in the susceptible cultivar was a direct function of cumulative effect of temperature. For cv. Marian Seefurth, there were significant linear relationships between degree-days and \%LAC in all three experiments. The effect of temperature on leaf colonization was also expressed as $\mathrm{LAC}_{50}=$ $\mathrm{C} / T$, or $\mathrm{C}=T \times \mathrm{LAC}_{50}$, in which $T$ is the average of minimum and maximum temperatures and $\mathrm{C}$ is the constant. Both relationships indicate that colonization of leaf tissues progresses faster at higher temperatures, and the average of minimum and maximum temperatures is the key parameter for calculating \% LAC.

The clear effect of temperature on \%LAC obtained for cv. Marian Seefurth also suggests that multiplication of the pathogen in leaf tissues is controlled by temperature, but not restricted by the host defense mechanisms. The in vitro study showed that cell growth of $X$. campestris pv. dieffenbachiae in a broth medium was enhanced with increased temperature, maximized at $30^{\circ} \mathrm{C}$, and slightly leveled off at $32^{\circ} \mathrm{C}(1)$. However, cv. Kalapana was less sensitive to temperature changes than was cv. Marian Seefurth, and no clear relations were evident between degree-days and \% LAC for $\mathrm{cv}$. Kalapana. This suggests that the defense mechanism for disease resistance overshadows the temperature effect and restricts multiplication of the pathogen in leaf tissues of the resistant cultivar.

Three linear relationships between degree-days and \% LAC for cv. Marian Seefurth were nearly identical, despite the fact that the experiments were conducted in the glasshouses and growth chambers with fluctuating relative humidity as a function of temperature. This suggests that temperature, rather than relative humidity, primarily controls the rate of leaf colonization. In general, leaf 
wetness and water congestion in leaf tissues, caused by a prolonged period of high relative humidity, enhance bacterial infection (19,22-24). Growth and survival of bacteria are expected to be more stable once the cells enter the leaves, because the availability of water is more constant in the intercellular spaces than on the leaf surface (3). For bacterial blight of anthurium, relative humidity appears to be critical only in the stage of invasion of the pathogen to the leaf, but not after the pathogen infects and colonizes the leaf tissues. In this study, the inoculated plants were kept wet overnight (for approximately 16 to $18 \mathrm{~h}$ ) in sealed plastic bags. As judged from numerous inoculation tests in the past, this period of leaf wetness is sufficient for attaining the maximum incidence of leaf invasion by the pathogen. During the experiments, all plants were watered with sufficient amounts of water, and no plant showed signs of wilting even in the growth chamber set at the highest temperature regime. Perhaps, the availability of water in the leaf tissues is maintained above the sufficient level for the maximal growth of the pathogen within the conditions tested in this study.

The linear relationship between degree-days and \%LAC provides a mathematical estimate of \% LAC at different times following inoculation. The linear relationships had degree-day intercepts in all cases, indicating that a certain threshold degree-day is required to detect the first signal of leaf colonization using bioluminescence. The detection limit of the bioluminescence technique was $>10^{6} \mathrm{CFU} / \mathrm{cm}^{2}$ (or $>10^{4} \mathrm{CFU} / \mathrm{mm}^{2}$ ) of the leaf tissues (7). Therefore, the intercept represents the degree-day threshold required for the pathogen population to reach at least $10^{4} \mathrm{CFU} / \mathrm{mm}^{2}$ in the leaf tissues (544 to 573 degree-days for cv. Marian Seefurth). It also represents the time when leaf colonization by the pathogen starts to advance.

The slope represents the increase of \%LAC per degree-day. The average total leaf area of cv. Marian Seefurth plants used in the three experiments was $94.4,85.3$, and $111.2 \mathrm{~cm}^{2}$. Thus, the daily increase of leaf colonization based on the corresponding slopes is calculated as $0.0928,0.0833$, and $0.0994 \mathrm{~cm}^{2}$ per degree-day, respectively. From these values, the daily increase of colonized leaf area in cv. Marian Seefurth is estimated as 1.8 to $2.2 \mathrm{~cm}^{2}$ in winter or 2.1 to $2.5 \mathrm{~cm}^{2}$ in summer. Assuming that colonization of leaf tissues progresses at the same rate in plants of different sizes, $\mathrm{LAC}_{50}$ can be achieved in only 2 to 4 days after colonization starts to advance in smaller plants with leaves of 10 to $20 \mathrm{~cm}^{2}$. Whereas, in larger plants grown in production fields (with leaves of $>500 \mathrm{~cm}^{2}$ ), $\mathrm{LAC}_{50}$ may not be achieved until $>100$ days after leaf colonization starts to advance. Likewise, smaller plants are killed rapidly as the pathogen advances from leaves to petioles and the main stem. In contrast, larger plants may be saved by removing infected leaves before the disease becomes systemic.

The incubation period was estimated from the relationship between degree-days and symptom development. Unlike the relationship obtained for \%LAC, the relationship between degree-days and \%LAS was exponential rather than linear. Visible symptoms (watersoaking and necrosis) develop in succession; therefore, the relationship consists of two different functions. The linear increase in visible symptoms at the early stage of disease development represents formation of water-soaked areas, and the exponential increase at the later stage represents rapid development of necrotic lesions. Assuming that the pathogen invasion occurs at the time of inoculation, the degree-day intercept represents incubation period. The calculated degree-day intercept of a regressed line in the linear phase of the exponential relationship was 520 degree-days. The calculated degree-day intercept of the linearized relationship for logtransformed data was 2.70 log degree-days, or 496 degree-days. From these measurements, the incubation period was determined as approximately 500 degree-days for cv. Marian Seefurth.

The calculated degree-day intercept for \% LAS was slightly smaller than that for \% LAC. In reality, however, detection of bioluminescence was always synchronized with symptom expression at the initial stage of disease development. The difference in degreeday intercepts was likely due to the result of mathematical adjust- ments of biological events. Therefore, both types of assessment should be equivalent in estimating the time of initial symptom development. The degree-day intercept for \%LAS determined by visual assessment could substitute for the degree-day intercept for $\%$ LAC if the bioluminescence technique is not available.

The degree-day-based relationship and specific key values obtained for the progress of bacterial blight are useful for characterizing a disease outbreak and hence improving the strategy of disease control. Under the typical weather conditions in Hilo (based on the monthly data for 1981 through 1996 reported by the National Climatic Data Center, Asheville, NC), the predicted incubation period based on 500 degree-days is 23 days in winter (average temperature of $21.7^{\circ} \mathrm{C}$ ) and 20 days in summer $\left(25.1^{\circ} \mathrm{C}\right)$. Thus, when new symptoms are observed on leaves of susceptible plants, infection can be traced to the location and condition where the plants were grown 3 to 4 weeks earlier in winter or 2 to 3 weeks earlier in summer. The stage of disease development also can be estimated by knowing the specific value of $\mathrm{C}$, or degree-days at $\mathrm{LAC}_{50}$, for each cultivar. Moreover, the negative images of bioluminescence on X-ray films revealed that the pathogen had already advanced into the petioles by the time that half of the leaf area was colonized by the pathogen. Such advanced infections usually result in systemic infections and death of the plants (6).

For the resistant cv. Kalapana, temperature had little or no effect on incubation period and subsequent colonization of leaf tissues, as judged by the progress curves for leaf colonization. Nonetheless, symptoms in cv. Kalapana were first observed approximately 3 weeks following inoculation. The degree-day intercepts for \%LAC for cv. Kalapana were 534 to 584 degree-days, which is similar to what was observed for cv. Marian Seefurth (544 to 573 degreedays). However, the slopes of the regression lines for cv. Kalapana were significantly lower than those for cv. Marian Seefurth in all three experiments. These results indicate that the rate of leaf colonization by the pathogen rather than the incubation period determines cultivar susceptibility. In additional experiments, the same phenomena were seen in other cultivars (e.g., ARCS and UH1060; R. Fukui, unpublished data). The results suggest that the host defense mechanisms activated by the disease resistance genes restrict multiplication of the pathogen only after symptom expression or after the population reaches $10^{4} \mathrm{CFU} / \mathrm{mm}^{2}$ in leaf tissues. The slopes in the relationships between degree-days and \%LAC (or the values of C) may be used as cultivar-specific indices for disease resistance or for alternative disease ratings to evaluate effects of pesticides or biocontrol agents on disease suppression.

Under the coolest conditions in this study, \%LAS was not considerably different between cv. Marian Seefurth (9.0 to 17.1\%) and cv. Kalapana (4.9 to $11.5 \%$ ), even on the third visual assessment (Figs. 3 and 4). However, the difference was pronounced at higher temperatures. This may explain the earlier field observations that the rise in temperature of only a few degrees may have significant implications in disease epidemics $(2,9)$. The design and aeration of glass and shade houses can be modified to lower temperature for a few degrees with significant benefits in terms of lowering disease severity $(10,11)$.

The incubation period for the systemic phase of infection is considerably longer than that for the foliar phase of infection, especially in resistant cultivars (7). Systemically infected cv. Kalapana plants survived for at least 15 weeks without expressing visible symptoms. Thus, unrelenting vigilance is needed to prevent spread of the disease to clean plants. Detailed information on incubation period for the systemic phase of infection and its relation to temperature would help to establish a highly dependable strategy for preventing disease spread from infected but symptomless plants.

\section{ACKNOWLEDGMENTS}

This research was supported, in part, by the United States Department of Agriculture/Special Grants Program for Tropical and Subtropical Agri- 
cultural Research (Agreement No. 96-34135-2841). College of Tropical Agriculture and Human Resources Journal Series No. 4435. We thank S. C. Nelson for critical reading of the manuscript and A. K. Nishii for technical support.

\section{LITERATURE CITED}

1. Alvarez, A. M., Lipp, R., Norman, D., and Gladstone, L. 1990. Epidemiology and control of anthurium blight. Pages 27-30 in: Proc. Anthurium Blight Conf., 3rd. A. M. Alvarez, ed. HITAHR (Hawaii Inst. Trop. Agric. Human Resources) J. Ser. 05.07.90. Univ. Hawaii Manoa, Honolulu.

2. Alvarez, A. M., Norman, D., and Lipp, R. 1991. Epidemiology and control of anthurium blight. Pages 12-18 in: Proc. Hawaii Anthurium Ind. Conf., 4th. A. M. Alvarez, D. C. Deardorff, and K. B. Wadsworth, eds. HITAHR (Hawaii Inst. Trop. Agric. Human Resources) J. Ser. 06.18.91. Univ. Hawaii Manoa, Honolulu.

3. Beattie, G. A., and Lindow, S. E. 1995. The secret life of foliar bacterial pathogens on leaves. Annu. Rev. Phytopathol. 33:145-172.

4. Chang, R. J., Ries, S. M., and Pataky, J. K. 1992. Effects of temperature, plant age, inoculum concentration and cultivar on the incubation period and severity of bacterial canker of tomato. Plant Dis. 76:1150-1155.

5. Duveiller, E., and Maraite, H. 1995. Effect of temperature and air humidity on multiplication of Xanthomonas campestris pv. undulosa and symptom expression in susceptible and field-tolerant wheat genotypes. J. Phytopathol. 143:227-232.

6. Fukui, H., Alvarez, A. M., and Fukui, R. 1998. Differential susceptibility of anthurium cultivars to bacterial blight in foliar and systemic infection phases. Plant Dis. 82:800-806.

7. Fukui, R., Fukui, H., McElhaney, R., Nelson, S. C., and Alvarez, A. M. 1996. Relationship between symptom development and actual sites of infection in leaves of anthurium inoculated with a bioluminescent strain of Xanthomonas campestris pv. dieffenbachiae. Appl. Environ. Microbiol. 62:1021-1028.

8. Fukui, R., Muroi, H., Nelson, S. C., and Alvarez, A. M. 1995. Effects of temperature and nitrogen fertilization on infection process in leaves of anthurium inoculated with a bioengineered, bioluminescent strain of Xanthomonas campestris pv. dieffenbachiae. (Abstr.) Phytopathology 85:1164.

9. Graser, E. A., Higaki, T., Imamura, J. S., Furutani, S. C., Sakai, W. S., Tsang, M., and Sewake, K. T. 1991. Shadehouse microclimates and anthurium blight. Pages 31-32 in: Proc. Hawaii Anthurium Ind. Conf., 4th. A. M. Alvarez, D. C. Deardorff, and K. B. Wadsworth, eds. HITAHR (Hawaii Inst. Trop. Agric. Human Resources) J. Ser. 06.18.91. Univ. Hawaii Manoa, Honolulu.

10. Graser, E. A., and Xia, H. 1994. The microclimate in a large shade house and anthurium blight. Pages 28-29 in: Proc. Hawaii Anthurium Ind. Conf., 5th. K. M. Delate and C. H. M. Tome, eds. HITAHR (Hawaii Inst. Trop.
Agric. Human Resources) J. Ser. 02.02.94. Univ. Hawaii Manoa, Honolulu. 11. Graser, E. A., and Xia, H. 1994. A comparison of the microclimate under poros cloth, plastic cover and hapuu. Pages 22-29 in: Proc. Hawaii Anthurium Ind. Conf., 6th. K. M. Delate and E. R. Yoshimura, eds. HITAHR (Hawaii Inst. Trop. Agric. Human Resources) J. Ser. 09.12.94. Univ. Hawaii Manoa, Honolulu.

12. Koizumi, M. 1976. Incubation period of citrus canker in relation to temperature. Bull. Fruit Tree Res. Stn. Ser. B, Okitsu 3:33-46.

13. Nishimoto, T., and Fujimori, T. 1996. Influence of inoculum concentration, temperature and humidity on the disease of annual bluegrass caused by Xanthomonas campestris pv. poae JT-P482. Ann. Phytopathol. Soc. Jpn. 62:492-494.

14. Norman, D. J., and Alvarez, A. M. 1994. Latent infections of in vitro anthurium caused by Xanthomonas campestris pv. dieffenbachiae. Plant Cell Tissue Organ Cult. 39:55-61.

15. Ott, L. 1984. An Introduction to Statistical Methods and Data Analysis. Duxbury Press, Boston.

16. Sathyanarayana, N., Reddy, O. R., and Latha, S. 1998. Interception of Xanthomonas campestris pv. dieffenbachiae on anthurium plants from the Netherlands. Plant Dis. 82:262.

17. Shehata, S. A., and Nishijima, W. T. 1989. The impact of anthurium blight on the profitability of the industry. Pages 17-19 in: Proc. Anthurium Blight Conf., 2nd. J. A. Fernandez and W. T. Nishijima, eds. HITAHR (Hawaii Inst. Trop. Agric. Human Resources) J. Ser. 03.10.89. Univ. Hawaii Manoa, Honolulu.

18. Shehata, S. A., Nishimoto, M., and Hamilton, M. 1990. The impact of anthurium blight on the profitability of the industry. Pages 3-6 in: Proc. Anthurium Blight Conf., 3rd. A. M. Alvarez, ed. HITAHR (Hawaii Inst. Trop. Agric. Human Resources) J. Ser. 05.07.90. Univ. Hawaii Manoa, Honolulu.

19. Stall, R. E., Gottwald, T. R., Koizumi, M., and Schaad, N. C. 1993. Ecology of plant pathogenic xanthomonads. Pages 265-299 in: Xanthomonas. J. G. Swings and E. L. Civerolo, eds. Chapman and Hall, London.

20. Takanashi, K. 1978. Ecological studies on bacterial shot hole caused by Xanthomonas pruni (E. F. Smith) Dowson. Bull. Fruit Tree Res. Stn. Ser. A 5:1-71.

21. Vauterin, L., Hoste, B., Kersters, K., and Swings, J. 1995. Reclassification of Xanthomonas. Int. J. Syst. Bacteriol. 45:472-489.

22. Wiles, A. B., and Walker, J. C. 1952. Epidemiology and control of angular leaf spot of cucumber. Phytopathology 42:105-108.

23. Williams, P. H., and Keen, N. T. 1967. Relation to cell permeability alterations to water congestion in cucumber angular leaf spot. Phytopathology 57:1378-1385.

24. Zehr, E. I., Shepard, D. P., and Bridges, Jr., W. C. 1996. Bacterial spot of peach as influenced by water congestion, leaf wetness duration, and temperature. Plant Dis. 80:339-341. 